\title{
Obstacles in Learning English as a Second Language among Intermediate Students of Districts Mianwali and Bhakkar, Pakistan
}

\author{
Tahir Jahan Khan1, Nasrullah Khan ${ }^{2 *}$ \\ ${ }^{1}$ Awang Had Salleh Graduate School of Arts and Sciences, Universiti Utara Malaysia, Sintok, Malaysia \\ ${ }^{2}$ Department of Electrical Engineering, COMSATS Institute of Information Technology, Islamabad, Pakistan \\ Email: *tjniazi9@gmail.com, nasrullahk@yahoo.com
}

Received 8 January 2016; accepted 22 February 2016; published 25 February 2016

Copyright (C) 2016 by authors and Scientific Research Publishing Inc.

This work is licensed under the Creative Commons Attribution International License (CC BY). http://creativecommons.org/licenses/by/4.0/

c) $\underset{\mathrm{EY}}{\mathrm{C}}$ Open Access

\begin{abstract}
No one can dispute the assertive position of English as a communicative language. It is enjoying status of medium of instruction as well as compulsory subject in Pakistan. But it is facing numerous problems in learning. The failure rate of the students is increasing which is deplorable. The failure in this subject means the failure in the public examinations. The concerns about the situation can be observed by all the stakeholders. The recent study is an attempt to probe into the alarming situation that has been conducted in the male colleges of public sector of Districts Mianwali and Bhakkar, the remotest Districts of Pakistan. This study deeply looks into the obstacles faced by the intermediate collegiate students in learning it. Four out of seven public sector colleges of both districts have been selected; taking from urban and rural areas to get genuine and reasonable data in this connection. The study has examined the position of English in the presence of Urdu and Saraiki, the mother tongues of students with the background of the brief survey of the position of English and the learners of it. Many factors have been indicated that are responsible for creating obstacles in learning English. Results point out that students of the context desire to learn English but numerous factors stand on their way of progress that need to be eradicated for the better future of this language. The ambiguous educational policies, the bias attitude towards English, the behavior of parents and teachers, the adverse policies of the government, the unavailability of modern teaching technology to the public sector, the shortage of English teachers especially in the remotest located colleges, the flawed syllabi and examination system, the lack of teaching training and the deprived position of teachers are the major factors that are arising obstacles in learning English. The study emphasizes upon the state support by adopting positive approach to the issue to strengthen the position of English.
\end{abstract}

"Corresponding author.

How to cite this paper: Khan, T.J. and Khan, N. (2016) Obstacles in Learning English as a Second Language among Intermediate Students of Districts Mianwali and Bhakkar, Pakistan. Open Journal of Social Sciences, 4, 154-162. 


\section{Keywords}

\section{English Language, Training, Syllabi, Behaviour}

\section{Introduction}

This study is an attempt to explore and identify the obstacles in learning English among the male intermediate students of public sector of Distt. Mianwali and Bhakkar, the southern districts of the Punjab, Pakistan. It inquiries into the matter of interferences and implication of mother tongues, Urdu and Saraiki with English (L2) as a second language in the light of social aspects and the educational policies of the country. Mianwali and Bhakkar are the two main districts of southern Punjab, where the students from various social backgrounds, study in the public sector institutions and they face obstacles and hindrances in the subject of English as a second language. They learn English, as a second and foreign language, in their educational institutions along with the using of their local and regional languages in their surroundings. This study aims at exploring all these trends with a view of looking at the obstacles in learning English for the students of intermediate of the public sector colleges.

\section{Purpose}

The purpose of this paper is to explore the factors which hurdle on way of learning English at Intermediate level of the students of Districts Mianwali and Bhakkar, two remotest areas of Pakistan. This study examines that how the students are facing obstacles in learning English as a second language besides the interference and implication of their various mother tongues and regional languages during their academic course of intermediate level in various colleges of the region.

The students learn English, as a second and foreign language, in their educational institutions along with the using of their local and regional languages in their surroundings. This study aims at exploring all these trends with a view of looking at the obstacles in learning English for the students of Intermediate of the public sector colleges of Pakistan.

\section{Significance of the Study}

English, being an international and communities' language, is enjoying a powerful status of medium of instruction in Pakistan since after the partition. It is also enjoying a place of compulsory subject among many other subjects of the syllabi in the institutions of the country. Many efforts have been made to give it highly acceptable and due place in the society of Pakistan according to the new modern challenges of the world [1] [2].

It is the language that helps us developing our trade and relations with the rest of the world. It is also admitted and acknowledged that the native people of this language, with the help of it, have been ruling the whole world; and this effect truly can be traced out in our past history of the country. It is the language with which the English people have been ruling over the sub-continent. They landed on the shore of sub-continent as the traders, but gradually, seeing the favorable circumstances, they ventured to hold firm grip over its economy. English, as a language, starts rooting in this vast land of the Muslims and Hindus. With the passage of time, English has been thrust its way into the heart of our national life that it has become a matter of our survival. It is why, because this modern world, breaking all barriers, has shrunk in its size of a global village.

In this global village, many people inhibit and they use different languages but English is a language that enables them in crossing and breaking all barriers and hindrances of geographical and linguistics. It helps them in communicating with one another, and so they have become one citizen of the same world regardless racial and national prejudices. But it remains as a second and foreign language in the countries, so after the existence of two separate states, English still enjoying its status in our country. It has been facing obstacles and difficulties in learning it. It has been facing many challenges in its implication in our society. These challenges are not found only in its learning but also in its methods of teaching, and it is why our learner faces obstacles in learning it.

This study aims at exploring these difficulties and obstacles that create hindrance in way of learning as well as in the development. This attempt not only points out these obstacles, but also presents recommendations. With the change in the student demographics, there is a need for engaging learners in taking full responsibility for 
their language learning. There is also a need for teachers who are not only language experts but who are also trained in the use of technology and who can facilitate foreign language learning in a better way with the help of modern technologies.

\section{The Problem}

The learners of English at Intermediate education level are facing many obstacles in learning English as second and compulsory subject. They desire to achieve competency over the language and for this reason, they also try hard; but they cannot remove these hurdles in way of their progress. In spite of so much effort, the result in learning this subject is dismay. The failure in this subject means failure in whole and all subjects at this level of Intermediate. In spite of the considerable and immense efforts for the teaching of English, the results are deplorable [3]. According to [1], "failure in English means failure in the entire" examinations. "High rate of failure affects students in two ways: it destroys their opportunities for white collared jobs in the country and also destroys their morale" [4]. The problems of our learners are manifold and need attention to be solved. These multifaceted problems have been indicated in many studies [1] [2] but these have not been addressed comprehensively.

The present study is a venture to look into the obstacles in learning English. Many attempts have been made in indicating the difficulties in learning English as a second language [2] [5] [6]. These have pointed out many factors which are creating problems in learning English. However, the learning obstacles among Intermediate college students have not been addressed extensively. These studies have not been extended to this important context which prepares the students for getting higher education or practical life by adopting various professions.

Therefore, this study has not only pointed out obstacles extensively but also recommends suggestions for implications. It does not only enquire into the matter but also provides guide lines. This study will be helpful for the learners to look into their odds and obstacles in its way of learning; and then furthermore they would be motivated to study English with zeal and enthusiasm. They would feel comfortable in using it as a vehicle of intercommunication with the world outside.

\section{Objectives of the Study}

This study has following objectives.

1. To examine the obstacles in learning English as second language among the Intermediate collegiate students of the two Districts, Mianwali and Bhakkar, the remotest regions of Pakistan.

2. To present the ways to improve the declining condition of learning English as second language.

3. To provide guidance for future among the students of Pakistani context.

\section{Research Questions}

This study aims at answering to these questions:

1. What are the obstacles in learning English as second language being faced by the Intermediate students of Districts Mianwali and Bhakkar of Pakistan?

2. How these obstacles can be removed among the learners of English, as a second language, among Pakistani Intermediate, collegiate' students?

3. How the recommendations of this study can be implied among parents, teachers and students for improving these obstacles for learning English as second language in the country?

\section{Literature Review}

Obstacle or difficulty means a concept with objective and subjective validity. It is defined as a task that requires effort or labor to solve. In the light of such observation, obstacle may be measured in many ways as quoted Newell \& Simon (1972) as cited in ITS (nd) [7]. This study is going to explore the obstacles in learning English academically. But this study does not intend to look at the issue as has been observed by [8]. Such obstacles and problems in language learning arise when there is no organism between available data and grammar [9] as quoted by [8].

Learning English at Intermediate level is concerned only with the obstacles that a learner faces during reading 
and writing English for qualifying his public examination. Because, in our context of study, the learners use Saraiki and Urdu respectively as their mother tongue and their home cultures are critical to the development of written language models of reading and writing in English as a second language and compulsory subject. In such situation, the learners are at disadvantage for success because they face many obstacles as Gay (1988) and Snow (1992) have been cited in [10].

At intermediate level, English is being taught as a compulsory subject in the context. Obstacles mean the problems, hurdles and difficulties in way of learning English at this level. Examination system, students' weak position and foundation in English, large classes, passive learning, uninteresting, lengthy, difficult literature based syllabi, the poor performance of the English teachers and old methodologies are considered to be major problems in the learning English [4]. The annual results of the students of our country indicate the sheer increase in failure and it is all due to failure in the subject of English. The failure of English means the failure in all subjects. In the opinion of Abbas [1] [3] reveals the fact that in spite of so many efforts, the result in English remains poor and this is all due to "flawed pedagogy and material design".

Regarding the function of a language, each language has four skills as Listening, Speaking, Reading and Writing. The disability or competency over a language varies as the diversity of the socio-linguistic division in this world. As Morley (1972) as cited by [11] has observed that listening gets complexity and difficulties in a place where it is being used as non-native language. In this way, the significance of the Speaking skill is of great importance and its importance cannot be denied (Bailey and savage 1994) as cited by Lazaraton in [11]. Brown (1994) also cited by Lazaraton in [11] Celce-Murcia (2001) has mentioned many factors that make it a challenging skill of English language. Reading is a socio-interaction process in which "a text", "a reader" and "social context” are involved Bernhardt (1991) as cited by Ediger in [11]. But Grabe (1991) as referred by Ediger in [11] has mentioned the difficulties in learning this.

Pakistan is a country where Urdu is her national language and besides Urdu there are numerous regional languages that are being used to communicate. The role of these languages is more significant. Pakistan was a part of sub-continent that has been ruled by the various nations and before partition it has been ruled by the British; and for these reasons, the people of Pakistan look to be influenced by different languages and cultures [12]. The $10.53 \%$ of population of the place of this study, uses Seraiki as shown in [12]. To some extent it is presumed these contextual fact hindrances in way of learning English. The people of this context do not like to avoid their own language and they prefer to use it in their daily life. Their attachment to their own language is naturally acknowledged fact. Then these groups are divided among so many other groups and each group culturally, linguistically and traditionally vary from one another. Each region has its own language. Urdu is having a national position while English is also enjoying a medium of instruction in these regions [13]. In our context of study, the learners are the Intermediate students. It means that they already have learnt their mother tongue and their national language. But the obstacle arises in learning English at their colleges. The children and adults face same obstacles but the logical problem that adult learners face at this level is different, quoting [8] (nd) as cited in [8]. Many scholars agree that there is difference between native speakers and non-native speakers of second language learning. The learners of our context are the students with the background of many other languages and these learners face the obstacles in learning English in the way as the immigrant children of diverse language background face in their school setting in Australia Pauline Gibbons (1993). These students face obstacles as referred "comprehensible input" as advanced by [14]. The obstacles arise when there is lack of understanding between a context where a learner lives and the difficulty of a language task given to the students [15]. Most of the obstacles arise because the unconsciously the use and interference of L1 occur. The learners are in habit of using their mother tongue, so in this way they face a lot of obstacles in learning English as a second language during their educational career. Krashen (1981) [14] has quoted [16] that "syntactic errors in adult performance" occur due to the use of mother tongue in the life of a learner and this impact remains for a long period in the mind of a learner as cited Banathy, Trager, and Waddle (1966) by Gumperz [17] and S. Dill (1971). In this way, such errors or obstacles are difficult to trace out as it has become an unavoidable habit in the life of learner. Krashen (1981) [14] has remarked that such errors or obstacles vary as the learners vary in their respective linguistic background and he has quoted Richards (1971) and Buteau (1970) in this regard.

\section{Research Methodology}

The quantitative and qualitative, both, research approaches are going to be used in this study by the researcher. The quantitative data has been collected through a questionnaire containing close-ended items from the teachers 
and also likewise, another questionnaire has been developed for the collection of quantitative data from the students. The data obtained from these both questionnaires has been analyzed quantitatively through the use of Microsoft Excel. For the collection of qualitative data and its analysis, interviews have been conducted of the male Intermediate students of four public sector colleges of Distt. Mianwali and Bhakkar. The qualitative approach as advocated by [18] has been used to make a dissertation acceptable.

According to the advocacy of Brian Patridge and Sue Starfield [19] the research methodology has been adopted for this study to get data in this study. Survey research strategy has been used for the collection of data and information through the distribution of questionnaires among the 10 English teachers and 65 male Intermediate students of 4 public sector colleges of Distt. Mianwali and Bhakkar. These questionnaires have been developed with close-ended items. Interviews of 7 students have been conducted. Survey Research Strategy is considered as a best resource in a study as it enables a researcher to get the result of a study. According to [20] in surveys further explanation for the clarification might be avoided for the sake of standardization on the side of respondent and a respondent can infer what a researcher desires to get.

\section{The Findings}

The study is an attempt to explore the obstacles in learning English and it has been brought to light that there are obstacles in learning English. Through the data collected, it has been revealed that the students are facing problem in learning English. The study conducted shows that all teachers and students have reported that students are facing obstacles in learning English. These are as following.

\subsection{Large and Overcrowded Classes}

The study conducted reveals that the obstacles are occurring due to large size of the classes. The majority of the teachers are teaching a class size of less than 60 students. It further shows that a big majority of teachers is not satisfied with the class size they are teaching. It also has been interestingly noted that no teacher has reported to be very satisfied with his large class size. The distinctive feature of public sector institutions is a large and over-crowded classes but without the teaching and other facilities [21]. This survey has revealed this fact that most of the respondents are teaching large classes that have the learners more than 80 . Large classes have many problems. As pointed out by Gibbs and Jenkins (1992) [22], the increase in the number of the students as in the large classes, many difficulties in teaching and learning occur. But as pointed out by Xu (2001) [23], the class size has no significance, but most of the researchers agree that small class gives better result for so many factors. In this way, Malik (1996) [4] agrees that in the presence of poor and worn out teaching methodology creates obstacles and hindrances in way of teaching and learning to the large classes in our context. Most of the respondents have expressed their disliking of large classes of English.

\subsection{Role of Motivation}

The study presents a data that a majority of students are motivated while many of the respondents are not motivated in learning English due to various factors. It suggests that the students are motivate but due to absence of many required needs for learning, they look not to be motivated. It emphasizes upon the need of creating motivation among students.

\subsection{Obstacles in Language Skills}

The English syllabi at Intermediate level are based upon purely only reading and writing. The respondents have expressed that most of the students are facing problem in both language skills and the reason is that the syllabi is literature oriented. The teachers read and explain the ideas but the students are not assigned any reading or writing activity as the practice work at college or home. Speaking skill has no practical role in the syllabi and obviously no attention, by the teachers as well as students, is given to this skill. All of teachers and students have expressed that the students face hurdles in speaking skill.

\subsection{Lack of Interest and Ruthless Attitude towards College Teachers}

In the light of this study, it has been revealed that there are two types of lecturers in the public sector colleges. One is regular and permanent through PPSC and the other are temporary based that are called contractual 
through the PPSC. They have different pay and other allowances. In the light of this survey, the lecturers in English are deprived of many financial and other facilities that create "anxiety and fear" as demonstrated by [24] and this fact creates many obstacles, and if a teacher is not satisfied with his career, how a good teaching of a subject can be expected. This situation is a main cause of occurring obstacles in learning English among most of the students. Then this study shows that that no teacher is willing to work and serve in the remotest area for so many reasons, as we have seen that there is no permanent and regular English teacher at G. C. EisaKhale (Distt. Mwi). The post of English lecturer has been lying vacant for last many years. This is the very dismal condition and due to unavailability of a teacher, is creating obstacles in learning English.

\subsection{Lack of Teachers' Training}

“The field of second language teaching has undergone many fluctuations and shifts over the years" (Kuhn 1970) as cited in [11]. The survey conducted for the purpose of the exploration the obstacles in learning English, shows only five out of ten English teachers have attended short refresher course to equip themselves with the requirement of new teaching methodologies. It shows that the majority of the teachers have not got opportunity to train themselves to learn the new challenges of teaching and learning. They are the same what they were before many years ago, and then how we can expect that they would bring a revolution in teaching and learning English.

\subsection{Shortage of College Teachers}

It has been brought to the notice with alarming and surprisingly under the survey conducted to exploring the obstacles in learning English that even there is no single regular English teacher to teach English in the far flung area like G. C. Eisa Khale (Distt. Mwi). It has been taken to the notice that since many years in back, no single English teacher has been posted in this college. The respondents have told that English is being taught here by the teachers of other subjects or the principal manages himself and sometime he himself takes English class in this college. It has been also taken to the notice of the researcher that sometime on the request of the principal or under the instructions and orders of the education department, G. C. Mwi deputes a teacher to teach English here in spite of the fact that even G. C. Mwi, itself, is suffering an acute shortage of English teachers where besides a large number of Inter and Degree students, master in English class is in progress. But, seeing the cold attitude of their patronage, education, and department, principal has decided to discontinue the running of post-graduation class. But, as the study shows, that the poor students cannot afford education that is available in other cities away from their native towns.

\subsection{Discouraging Behavior of Teachers}

In the third part of the questionnaire for the students, the respondents have been asked about the general remarks and the factors that are responsible for creating obstacles, most of them have remarked that their teachers are "non-cooperative" and so they face difficulty in understanding and learning English. But the study of the educationists and the rules for teachers, Goodland, indicate "Teachers have always been expected to set a good example for learners, to provide a model of behavior”. Then many of the respondents have pointed out that even their teachers' show discouraging attitude towards their learning. A student from G. C. Mwi has not mentioned the name of his class teacher but he has pointed out that the behavior of his teacher is adverse in this regard. According to Horwitz [24], the fear of negative evaluation hindrances in way of learning. It is noteworthy that the English teachers do not receive appreciation and encouragement what they deserve from their administration at their institutions.

\subsection{English Curriculum}

A few years back, the English curriculum for intermediate, part-1 (first year) has been revised after much harsh and bitter criticism especially from all concerned stakeholders, after many decades, but still new revised syllabi is receiving various criticisms from different quarters. The needs for revising its part-2 (second year) is also a demand of the students and teachers on the basis to meet the new changing challenging of the time. All these trends have been reflected in the received responses of this study. As observed by Memon [25] that education system of Pakistan is not performing well due to "defective curricula". The objection to previous and recent 
English curriculum is described as based upon the ideas that allure the learners to same old and fairy land away from enabling the students to face the modern changing of the globalize world. Then most of the respondents have objected that they are supposed to learn English as second language, but only 25\% of the whole English syllabi are of its language. In other words, it is literature oriented curriculum. Many of them have appreciated the Urdu or other classical version into English and they declare that attempt has been made to close English and our classical languages with one another for the better comprehension to the students.

One thing more, that has been observed through the survey that it has been become a tradition in our country that the syllabi is designed regardless realizing the needs of the teachers and learners. Taylor [26] has commented over the views of Jennifer Jenkins [22]' article that it has been a custom of ELT that it is expected from the learners of L2 that they would accept the materials regardless of their own needs and identities. So, in our own context, the teachers and the students have pointed out such situation. The present syllabus has been designed without knowing the needs of the teachers and learners.

\section{Implications}

This study suggests following recommendations for implication.

$>\quad$ English is not only a language of its natives but the number of non-natives has been increased [26].

$>\quad$ This quoted study has been done in the background of South Korea, but English as a lingua franca has been implied in our context, too. The international status of English needs to be realized in our context.

The study has demonstrated that most of the people of the context, even the stakeholders, are unaware of their needs for learning. It is essential that they should realize the importance of learning English. It is an acknowledged fact that the sun of the English language will never end. English is a language that is required in every walk of life of the future's world. The nations would survive who would be able to communicate with other nations of the world. FeritKilickaya has quoted Demircan [27] and remarks that now Turkey is a prosperous state of the world. She starts the realization of the English language in 1950 and it was the time when the economic and military powers were increasing in the world. Turkey realized that English, a compulsory subject, was only a means that would be helpful in linking with other developed nations of the world. We also need to work on the same lines if we want to see our country and nation prosperous. As compared to the study conducted by [1], the present study shows that the parents of the learners look to be annoyed with English language. There might be many reasons, but as far as the study of Mansoor [21] is concerned, it was conducted in urban areas, but recent study has been conducted in rural and urban but the remotest urban area of the country. Obviously, there is a contextual difference between two studies.

$>\quad$ The present study recommends that a vast majority of the students are learning in public sector institutions as compared with the private. This presents a picture that a vast majority of the students at intermediate level comes from the remotest and rural areas of the country. Majority of the students get education in the public sector institutions. According to the report conducted by National Education Census [28], there are 1882 colleges in the whole country, 1025 exist in public sector and 857 are in private sector. This report suggests that there is very little difference between public and private institutions. It also means that our best part of population is learning in the public sector colleges. Thus, here this present study recommends that private sector should be given importance to bridge over the gulf between public and private sector.

The main stakeholders of this study are the students and they have pointed out in the interviews and the English teacher's responses to the questionnaires that our English teachers are not equipped with modern teaching technology of the time. When Abbas (1998) points out as cited in [21] that "failure in English is attributed to flawed pedagogy"; means not that teachers are at fault, but it suggests "the lack of adequately trained master trainers, little emphasis on teaching practice and non-existence of a proper support/monitoring system for teachers” [25]. The recent research has demonstrated that only five out of ten English teachers have received teaching training after joining as lecturers many years back. The new comers are absolutely unaware of this type of training. After completion of Master in English, they directly have been selected for teaching English. They are ignorant of the teaching methodology of the time. Then, they have studied only literature of English, how it can be expected from them that they would teach language, too. Our syllabus is also literature oriented, but it would be discussed under separate heading. Thus seeing all previous studies, this research also recommends that the English teachers would be trained at times to cope with the modern challenges.

$>$ Syllabi should not be a stagnant pool but it should be molded, remoulded, modified and even remobi- 
lized to accept the new challenges of time and context. It needs to be contextualized so far the taught and learner both might feel pleasure and gaiety in the process of teaching and learning.

$>$ The study has shown that no doubt there are hurdles and obstacles in learning English for the students, but as shown in the interviews of the students and that have been mentioned earlier in the previous relevant chapters, the most of the students are interested in learning it. They have desired to overcome all difficulties and even the interviews of most of the respondents have unveiled the fact that they want to learn and they have admitted that they are aware of the status and significance of English. It is a fact that learning a language means to have an access to "empowerment", and so the students can approach to the power through the employment [13]. This fact comes to light through the conducted interviews with the students when they have related that they are studying and learning English to have an access to employment in the future. In our country, English is being implemented as second language and as a medium of instruction. The survey shows that majority of the learners are learning it to get empowerment. If it is so and the study has presented factual position, then why not English should be recommended as a medium of instruction in our institutions. It is the fact that English is also a medium of instruction in our institutions. It is also enjoying as second language in our country. It is not our mother tongue but it is performing "certain communicative functions" in our context [29]. The study dares to recommends that it should be honored as it deserves. The importance of English varies from region to region, but it is an acknowledged fact that as international language it is playing a vital role for the mutual relationship among the different nations.

$>$ Most of the respondents have complained that the examination system is based upon memory testing and rot. Then, they have also mentioned the common practice of unfair means, especially during the objective portion of the subject in the examination halls. Modern researchers have demonstrated, on the basis of their research in the subject of English as second language, that there should be harmony and well established relationship between teaching and testing, as quoting Alderson and Wall (1993), Saville and Hawkey (2004) by Taylor (2006) [26].

\section{Conclusion}

Exploration of the obstacles in learning is a daring venture to expose many issues. The study has come to the conclusion that there are obstacles in learning English at intermediate male students of the public sector colleges in our country. Due to interaction with their mother tongues, Urdu and Saraiki, most of the students hesitate in expressing themselves in English. Then, this study has observed that our country and its people have a part of sub-continent and the land have been ruled by the invaders without the consent and will of its inhabitant; therefore, the forefathers of the students do not like English being considered it to be a language of their past British imperials and masters. After, even, partition, the governments have not succeeded in making clear cut decision about the medium of instruction for the educational institutions.

\section{References}

[1] Mansoor, S. (2003) Language Planning in Higher Education: Issues of Access and Equity. The Lahore Journal of Economics, 8, 19.

[2] Rahman, T. (2006) Language Policy, Multilingualism and Language Vitality in Pakistan. Trends in Linguistics Studies and Monographs, 175, 73.

[3] Abbas, S. (1998) Sociopolitical Dimensions in Language: English in Context in Pakistan. Journal of Applied Language Studies, 23, 42.

[4] Malik, F.J. (1996) The Teaching of English in Pakistan: A Study in Teacher Education. Vanguard, Lahore.

[5] Kannan, R. (2009) Difficulties in Learning English as a Second Language. Vol. 8, ESP World. www.esp-world.info

[6] Shamim, F. (2008) Trends, Issues and Challenges in English Language Education in Pakistan. Asia Pacific Journal of Education. http://www.informaworlalld.com/smpp/title content=t713724324 http://dx.doi.org/10.1080/02188790802267324

[7] ITS (nd) Tutorial School. http://www.tuition.com.hk/academic/concept.htm

[8] Gass, S.M. and Schachter, J. (Eds.) (1989) Linguistic Perspectives on Second Language Acquisition. New York: Cambridge University Press. http://dx.doi.org/10.1017/CBO9781139524544

[9] Chomsky, N. (1965) Aspects of the Theory of Syntax. MIT Press, Mass, 5-6.

[10] Foertsch (1998) Second Language Learning. North Central Regional Educational Laboratory, Learning Point Asso- 
ciates.

[11] Celce-Murcia, M. (2001) Teaching English as a Second or foreign Language. 3rd Edition, Heinle \& Heinle Publisher, Boston.

[12] Mansoor, S. (2004) The Status and Role of Regional Languages in Higher Education in Pakistan. Journal of Multilingual and Multicultural Development, 25, 333-353.

[13] Rahman, T. (2002) Language, Idealogy and Power. Oxford University Press, Karachi.

[14] Krashen, S.D. (1981) Second Language Acquisition and Second Language Learning. Pergamon Press Inc., Oxford.

[15] Cummins, J. (1984) Bilingualism in Education: Aspects of Theory. Research and Practice, Longman, London.

[16] Lado, R. (1957) Linguistics across Cultures: Applied Linguistics and Language Teachers. University of Michigan Press, Ann Arbor.

[17] Gumperz, J.J. and Dill, A.S. (1971) Language in Social Groups. Stanford University Press, Stanford.

[18] Marshall, C. and Rossman, G.B. (2006) Designing Qualitative Research. Sage Publications, Thousand Oaks.

[19] Partridge, B. and Starfield, S. (2007) Thesis and Dissertation Writing in Second Language. Routledge, London.

[20] Foddy, W.H. (1994) Constructing Questions for Interviews and Questionnaires: Theory and Practice in Social Research. New Edition, Cambridge University Press, Cambridge, UK.

[21] Mansoor, S., Zafar, M., Hussain, N., Sikandar, A., Azam, S.I. and Tatari, S.K. (2005) English and Employment in Pakistan. Unpublished Summary Report, Aga Khan University, Centre of English Language, Karachi.

[22] Gibbs, G. and Jenkins, A. (1992) Teaching Large Classes in Higher Education: How to Maintain Quality with Reduced Resources. Kogan Page, London.

[23] Xu, Z. (2001) Problems and Strategies of Teaching English in Large Classes in the People's Republic of China. In: Herrman, A. and Kulski, M.M., Eds., Expending Horizons in Teaching and Learning, Proceedings of the 10th Annual Teaching Learning Forum, 7-9 February 2001, Curtin University of Technology, Perth, 7-9.

[24] Horwitz, E.K., Horwitz, M.B. and Cope, J.A. (1986) Foreign Language Classroom Anxiety. The Modern Language Journal, 70, 125-132. http://dx.doi.org/10.1111/j.1540-4781.1986.tb05256.x

[25] Memon, G.R. (2007) Education in Pakistan: The Key Issues, Problems and the New Challenges. Journal of Management and Social Sciences, 3, 47-55.

[26] Taylor, L. (2006) The Changing Landscape of English Implications for Language Assessment. ELT Journal, 60, 51-60.

[27] Demircan, Ö. (1988) DündenbugüneTürkiye'deyabancıdil [Foreign Languages in Turkey: From Past to Today]. Remzi Kitabevi, İstanbul.

[28] NEC (2005). http://www.gilanifoundation.com/homepage/Free_Pub/EDU/NATIONAL_EDUCATION_CENSUS_2005_Pakistan.p $\underline{\mathrm{df}}$

[29] Alderson, J.C. (2004) Foreword. In: Cheng, L., Watanabe, Y. and Curtis, A., Eds., Washback in Language Testing: Research Contexts and Methods, Lawrence Erlbaum, London, ix-xii. 